\title{
Correction to: Periodontal Disease Impairs Muscle Recovery by Modulating the Recruitment of Leukocytes
}

\author{
Bárbara Capitanio de Souza, ${ }^{1,4}$ Bibiana Franzen Matte, ${ }^{1}$ André Luiz Lopes, ${ }^{2}$ \\ Bruno Costa Teixeira, ${ }^{2}$ and Marcelo Lazzaron Lamers ${ }^{1,3}$
}

\author{
Correction to: Inflammation (2019) \\ https://doi.org/10.1007/s10753-019-01128-5
}

The original version of this article contained mistakes, and the authors would like to correct them.

The production made a mistake in the article title where the word "Periodontal" was changed to "Periodical." The correct article title is now presented above.

The original article has been corrected.

\footnotetext{
The online version of the original article can be found at https://doi.org/ 10.1007/s10753-019-01128-5

${ }^{1}$ Dentistry School, Federal University of Rio Grande do Sul (UFRGS), Porto Alegre, Brazil

${ }^{2}$ Laboratory of Exercise Research (LAPEX), College of Physical Education (ESEF), Federal University of Rio Grande do Sul (UFRGS), Porto Alegre, Brazil

${ }^{3}$ Department of Morphological Sciences, Federal University of Rio Grande do Sul (UFRGS), Porto Alegre, Brazil

${ }^{4}$ To whom correspondence should be addressed at Dentistry School, Federal University of Rio Grande do Sul (UFRGS), Porto Alegre, Brazil. E-mail: barbara.capitanio@gmail.com
} 